DOE/MC/32260 -- 5850

(DE98002055)

\title{
Lockheed Martin T-Rex: Preliminary Report
}

Topical Report

July 31, 1997
RECFIVED

241998

OSTI

Work Performed Under Contract No.: DE-FC21-95MC32260

For

U.S. Department of Energy

Office of Environmental Management

Office of Technology Development

1000 Independence Avenue

Washington, DC 20585
U.S. Department of Energy

Office of Fossil Energy

Federal Energy Technology Center

Morgantown Site

P.O. Box 880

Morgantown, West Virginia 26507-0880

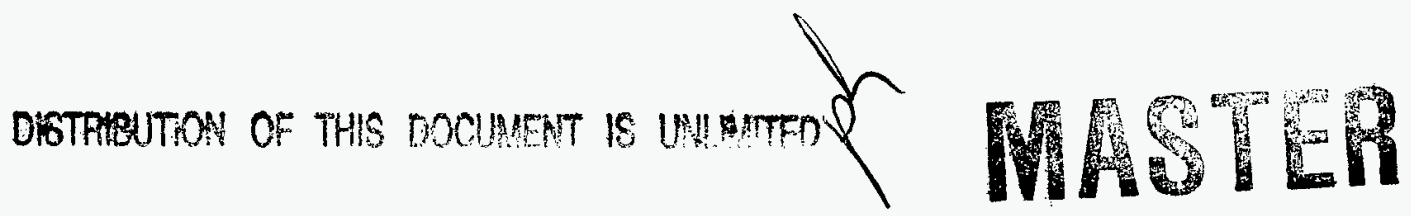

(DTIC QDALTTY TSEOEUTTR 3

By

Operating Engineers National Hazmat Program

250 Airport Circle

Beaver, West Virginia 25813 


\section{Disclaimer}

This report was prepared as an account of work sponsored by an agency of the United States Government. Neither the United States Government nor any agency thereof, nor any of their employees, makes any warranty, express or implied, or assumes any legal liability or responsibility for the accuracy, completeness, or usefulness of any information, apparatus, product, or process disclosed, or represents that its use would not infringe privately owned rights. Reference herein to any specific commercial product, process, or service by trade name, trademark, manufacturer, or otherwise does not necessarily constitute or imply its endorsement, recommendation, or favoring by the United States Government or any agency thereof. The views and opinions of authors expressed herein do not necessarily state or reflect those of the United States Government or any agency thereof. 


\section{LOCKHEED MARTIN T-REX \\ PRELIMINARY REPORT \\ TABLE OF CONTENTS}

Electrical Considerations $\ldots \ldots \ldots \ldots \ldots \ldots \ldots \ldots \ldots \ldots \ldots$

General Electrical Consideration $\ldots \ldots \ldots \ldots \ldots \ldots \ldots \ldots \ldots \ldots$

Trailing Cables $\ldots \ldots \ldots \ldots \ldots \ldots \ldots \ldots \ldots \ldots \ldots \ldots \ldots \ldots$

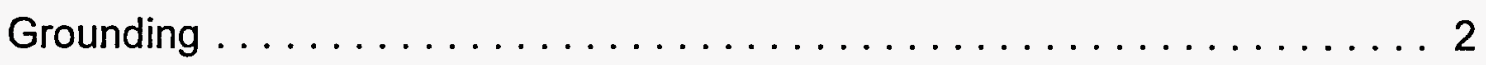

Surface High Voltage Distribution $\ldots \ldots \ldots \ldots \ldots \ldots \ldots \ldots \ldots$

Low and Medium Voltage Alternating Current Circuits $\ldots \ldots \ldots \ldots \ldots$

Potential for Harmful Human Factor Incidents and Enterprise Disablement . . 4

Exclusion Zone Emergency Maintenance $\ldots \ldots \ldots \ldots \ldots \ldots \ldots$

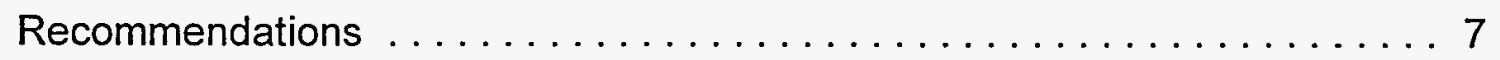




\section{LOCKHEED MARTIN T-REX \\ HUMAN FACTORS ASSESSMENT}

The assessment of the T-REX conducted at the Lockheed Martin facility was limited in its scope. The scope of the assessment was directed by the type of equipment being used and the amount of accessibility to the equipment. Due to severe time constraints the assessment was conducted in one day - human factors interface activities were limited. Therefore, this is being considered a preliminary assessment.

This report covers aspects of the technology that were available to the assessment team. Recommendations for future evaluation of this technology are also included.

\section{ELECTRICAL CONSIDERATIONS}

During the safety and health interface no plans were available to members of the evaluation team. Therefore, the following basic principles are suggested to the technology provider as a minimum basis of compliance with codes of prudent practices.

Recommendations include, but are not limited to, the following:

\section{General Electrical Considerations:}

Electrical H/S plan

Repair plan

Lockout/Tagout

Qualification/Certification of personnel to perform work

Examination, testing and maintenance

Conductors, capacity and insulation

Overload and short circuit protection

Switches

Lighting arresters

Transformers, installation and guarding

Resistors, location and guarding

Danger and warning signs

Inspection and cover plates

Insulating mats at power switches

Switchboards, passageways and clearances

Wiring and equipment installation and maintenance. 


\section{Trailing Cables:}

Trailing cables, short circuit protection, disconnecting devices

Trailing or portable cables, temporary splices

Permanent trailing cable splices

Clamping/attachment of trailing cables to equipment

Protection of trailing cables

Breaking of trailing cable

Handling of energized trailing cable

Rubber gloves and protective equipment, minimum qualification

\section{Grounding:}

- Grounding metallic sheaths, armors, and conduits enclosing power conductors

Grounding metallic frames, casings and other enclosures of equipment

Protection other than grounding

Grounding frames of stationary high voltage equipment receiving power from underground

Work/repair on high voltage lines, de-energizing and grounding.

\section{Surface High Voltage Distribution:}

Circuit breakers

Testing, examination, and maintenance of circuit breakers, procedures

Records of examination, maintenance of circuit breakers

Grounding resistors

Protection of high voltage circuits, neutral grounding resistors, disconnecting devices

Fail safe ground check circuits on high voltage resistance grounded

systems

High voltage trailing cables, minimum design requirements

Cable couples and connection boxes, minimum design requirements

Connection of single phase loads

Installation of high voltage transmission cables

Disconnecting devices

ID of circuit breakers and disconnecting switches

High voltage equipment, grounding

Movement of portable transformers and substations. 


\section{Low and Medium Voltage Alternating Current Circuits:}

Low and medium voltage circuits serve mobile three-phase alternative current equipment, circuit breakers

Testing, examinations and maintenance of circuit breakers, procedures

Protection of low and medium voltage three phase circuits

Disconnecting devices

ID of circuit breakers

Connection of single phase loads

Trailing cables supplying power to low

Voltage mobile equipment, ground wires and ground check wires.

Due to the fact that this particular technology may not be used in environments that have been characterized as toxic and/or flammable, the issue of permissibility must be taken into consideration.

Equipment such as the T-REX, performing work in flammable and potentially flammable environments, must be free of any unnecessary ignition hazards that may cause the initiation and propagation of fire or explosion. To accomplish this it is recommended that such technologies be manufactured to meet permissibility requirements.

Permissibility practices relate to the equipment which has been fabricated, assembled, or built in accordance with the approval, or any extensions thereof, issued by the Bureau of Mines of the Mine Safety and Health Administration in accordance with Schedule 2G, or any subsequent Bureau of Mines Schedule promulgated by the Secretary of Labor, or their official delegate, after March 30,1970, which amends, modifies or supersedes the permissibility requirements of Schedule $2 \mathrm{G}$, and maintained in permissible condition. Other relevant codes may also be applied.

Application of permissibility standards may include, but not be limited to the following:

- $\quad$ Pump motor

- $\quad$ Illumination devices

- Alarms

- $\quad$ Related warning devices

- Instrumentation 


\section{POTENTIAL FOR HARMFUL HUMAN FACTOR INCIDENTS AND ENTERPRISE DISABLEMENT}

- The potential exists for corrosion to occur and thus impede and/or disable the electrical circuitry of the technology. Integration of vapor- tight enclosures to segregate circuitry from chemical contact is suggested.

- Permissibility issues should be addressed to assure that the technology does not become a potential ignition source in flammable or explosive atmospheres.

The barrel grabber should be equipped with cushioning material that will enhance the gripping ability of the device and reduce the potential for damage to the barrel by unprotected components.

Non-sparking components should be considered for installation on end-effector attachments when the technology is intended for use in atmospheres where fire and explosion hazards may exist.

- Extend grease zirks on electric motor as well as other hard-to-reach locations so that the maintenance engineer is not placed in a potentially disabling physical or ergonomically compromising situation.

Compatibility of "O" rings on ram jacks and other components may require more than ordinary attention due to given chemical situations. Substitutions may be available for component parts.

- Connection hoses for end-effector attachments should be color coded or numbered to enhance sequencing and general application.

- Specific chemical hazard detection devices attached to the end effector would provide advanced warning and reduce worker potentials for contact with hazardous agents. These results could be monitored in the control cab or at remote operation locations.

The brackets used to hold the end effector connectors at the end of the boom appear to be placed too high for ease of operation.

Spillage of hydraulic oil which occurred upon separation of the end effector couplings causes notable complications in handling the couplings. Alternate methods may be considered for completing this task. Care should also be given to minimize spillage and its effect with any chemical agents at the site. 
- Safety chains and other sufficient guarding devices need to be provided on the catwalk of the technology to prevent accidents resulting from an inadvertent slip, trip, or fall on catwalk surface.

- The catwalk on the technology is rather narrow. This problem is even more prevalent when maintenance technicians are in Level A protective ensembles.

Hearing protection needs to be provided to any and all personnel engaged in activities in close proximity to the technology when it is in operation.

Radio communications should be used by all personnel engaged in activities in close proximity to the T-REX while it is in operation. The use of standard hand signals should be used only to supplement radio communications.

Remote pendant control may be more user friendly if rocker switches were installed instead of existing toggle switches. This observation was very pronounced when operators were in Level $A$ ensembles that required several layers of hand protection to be worn.

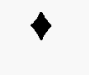

The trailing cable may be trammed over when operations are being performed remotely. The rigid extension does provide some increased mobility, but it may prove to be limited. Automated self-tailing devices may be considered for discussion and eventual integration.

- Extension of rigid cable trailing device might also be enhanced if it were longer.

Decontamination consideration and development of protocols and parameters for site-specific hazards need to be developed.

Illumination components may not be sufficient for worst case scenario or other intended use. Care should also be given to assure permissibility.

- Mounting the technology with Level A protective ensembles produced definite potentials for the occurrence of unwanted slips, trips, and falls.

- Deflation of protective ensembles prior to entering the cab for operation proved to enhance the operator's safety and efficiency.

Personal protective ensembles noticeably impaired operator's peripheral vision.

Mounting an auxiliary carry-out bottle for supplied airline systems must be considered. This is especially true if no provisions are made to mount a larger capacity air supply system on the technology for a secondary airline connection. 
- It was difficult for the operator to start the computer and operate the touch screen in the cab. This was attributed to the decreased dexterity encountered with the protective ensemble.

Dust control may be an important consideration. This will vary according to sitespecific conditions. Although much of the intended operation is to be performed remotely, the creation of dust may impair video transmission quality as well as contribute to explosive dust concentrations.

- Maintenance to the boom/stick, normally performed by maintenance engineers climbing members, will require a mobile platform with extension capabilities.

Since this equipment has been modified from diesel engine to electric, the considerations listed need to be followed to develop a more viable pre-operative plan.

\section{EXCLUSION ZONE EMERGENCY MAINTENANCE}

The research action team has identified disabling enterprise causal factors where emergency maintenance exercises may be required in the exclusion zone, even if only to prepare equipment for extraction from the exclusion zone.

Disabling enterprise causal factors identified by the research action team include, but are not limited to the following:

- Starter unit solenoids

- Restricted filters

- Hydraulic hoses to critical units

- Electrical system controls and/or generation

- Overheating

- Track off

- Disabled travel motors

- Disabled axle shaft(s)

Emergency maintenance of any of the above will require maintenance engineers to enter the exclusion zone with specifically designated levels of protection. This would significantly increase the time required to perform such activities as compared to the same tasks being performed without the above mentioned personal protective equipment.

It should be noted that some tasks were performed by the "dressed out" subjects (one in Level A protective ensemble) in the same time frame as the non-dressed (one wearing usual work clothes). Walking and equipment mounting times were somewhat longer for the dressed-out worker. Although many tasks were completed in virtually the same time the relative difficulty of accessing confined areas hampered the dressed-out 
worker. It should also be noted that the dressed-out worker completed all required tasks.

Concern has also been made regarding the spillage or other uncontrolled or noncontained release of materials resulting from disabling enterprise causal factors.

Release materials may include the following:

- Hydraulic oil

- Diesel fuel

- Engine oil

- Solvents

- Not otherwise specified solvents

- Not otherwise specified lubricants

The main concern regarding the above mentioned release of materials is the possibility of contamination of the immediate environment as well as any incompatibility and adverse reaction with on-site waste materials.

It is strongly suggested that a list of incompatible materials be placed into the site safety and health plan as well as in other standard operating procedures.

Although it appears that an experienced operator can perform traditional functions of the heavy equipment remotely through interface with the emerging technology, there are some fundamental issues that must be addressed. The most crucial of these is maintenance, in particular, maintenance operations to be performed in the exclusion zone of hazardous waste sites. These include:

- Exclusion zone emergency maintenance

- Disabled enterprise extraction

- Manual operation of the heavy equipment

- Routine servicing and maintenance in exclusion zone

\section{RECOMMENDATIONS}

Due to the narrow window of opportunity provided to the research action team for this evaluation, some recommendations are suggested for further evaluation of the technology:

- Preparation/assimilation of a complete Job Safety Analysis (JSA). Although many significant analytical points have been addressed in this report, it should be noted that more time would allow for a more complete evaluation and reporting. 
- A complete human factors interface should be conducted. This would provide not only an overview of general provisions, but would allow for a more intensive investigation into site-specific needs prior to their actual in situ interface.

- A Failure Mode and Effect Analysis would provide essential information regarding the potential for human factor harmful contact incidents, and possible mitigating actions.

- A Technology Safety Data Sheet (TSDS) would provide a quick reference relating to health and safety considerations, and would provide a foundation for selection and operation. A TSDS would aid decision-making by the purchaser, manager, safety professional, and worker.

- In situ evaluation of the technology would allow for the evaluation of technology utilization in its intended arena of operation, and would also allow for an evaluation of the overall process. This would provide data for assessment of enhanced evaluation and testing methodology, further development, and eventual integration where indicated.

- Baseline equipment evaluations and performance standards of the respective technology, as compared to that of traditional equipment, would allow the new technology to be challenged against the performance evaluation standards that have been validated for training and field operations. These standards have been developed and validated by the International Union of Operating Engineers and a host of health, safety, engineering, and allied professionals. It would also be of interest to all concerned parties to evaluate parameters that would include, the comparative analysis of those individuals utilized for the maintenance and operation (local and remote). Individuals would represent the following classifications: operating certified for the comparative technology, and a technician who has never operated the traditional technology in actual field application. Their performance should be measured by the previously mentioned validated criteria.

- Interaction and integration of the previously specified evaluation criteria to be incorporated into further development. The information provided may not only be of great assistance in the retrofitting of the technology but also provide a basis for the inclusion of the services provided by this organization to those in the research and development phases of any further emerging technology. 


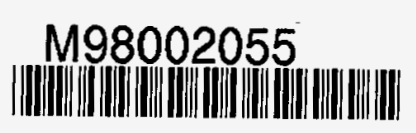

Report Number (14)DOE/MC/32260- -5850

Jubl. Date (11)

sponsor Code (18)

JC Category (19)

$$
\begin{aligned}
& \frac{1970731}{D O E / D E M, X E} \\
& U C-101, D O E / E R
\end{aligned}
$$

